\title{
Isolation of cellulose nanofibrils from coconut waste for the production of sewing thread
}

\author{
María Neftalí Rojas-Valencia', Elsa Galeana-Olvera ${ }^{1}$, Denise Y Fernández-Rojas ${ }^{1}$, Christian Mendoza-Buenrostro ${ }^{2}$, Hugo Alejandro \\ Nájera-Aguilar ${ }^{3}$ and Mabel Vaca-Mier ${ }^{4}$ \\ ${ }^{1}$ Institute of Engineering, National Autonomous University of Mexico, Mexico \\ ${ }^{2}$ Center of Innovation in Design and Technology, Tecnológico de Monterrey - Monterrey Campus, Mexico \\ ${ }^{3}$ School of Environmental Engineering, University of Science and Arts of Chiapas, Mexico \\ ${ }^{4}$ Energy Department, Autonomus Metropolitan University, Azcapotzalco Campus, Mexico
}

\begin{abstract}
Coconut waste is a by-product of commercial, industrial or agricultural activities, so that alternative uses for such waste are currently being sought. In Mexico, 66,203.22 tons of coconut waste were generated during the 2016 production cycle. Mexico City's Central Market produces $108,000 \mathrm{~kg} / \mathrm{year}$ of coconut fiber waste, which is sent directly to final disposal without being submitted to any type of treatment. Therefore, the general objective of this work was to find a way to use the cellulose nanofibrils obtained from coconut fiber residues to elaborate biomaterials that may substitute synthetic fibers in textile manufacturing.

The methodology was divided into two phases. The first phase, performed in Mexico City's Central Market, was field work focused on the study of the generation and sampling by quartering method based on Mexican Standard NMX-AA-15-1985. In the second phase, cellulose nanofibrils were obtained from the coconut fiber residues at laboratory level by means of a chemical method with sodium hydroxide. Subsequently, the cellulose nanofibrils were dissolved in a solution of 1 -ethyl3-methylimidazolium acetate and N, N-dimethylformamide. Then, this solution was mixed with PCL and acetone and introduced in an electrospinning device. According to the results of proximate and cell wall analysis, coconut fiber waste contains $28.72 \%$ cellulose. It was determined that the solution containing $16 \%$ cellulose by weight was the most appropriate for yarn manufacturing purpose. Because of their high resistance to biodegradation and their durability, coconut fibers are a suitable material for obtaining cellulose nanofibrils that can be used in the textile industry.
\end{abstract}

\section{Introduction}

The management of agricultural waste in Mexico is practically non-existent. There is currently no information regarding its generation at national level. None of the current waste prevention and integral management programs prepared and published by the state governments includes waste analysis, nor are strategies or specific actions for proper management and handling encompassed by them. Agricultural residues are those parts derived from the cultivation of different plant species, particularly during harvest, which are not intended for consumption. This category includes materials such as stems, leaves, husks, barks, pods, among others. Millions of tons of these residues are produced around the world and represent a source of abundant, cheap and easily accessible lignocellulosic biomass.

The processes that have been identified in the handling of these residues are mainly dispersed generation and disposal; on a smaller scale, collection and transfer, and in a rudimentary way, their use for the production of compost and/or animal feed. In other cases, the waste is burned. The present work exposes the environmental need to recover, reuse and recycle solid agricultural organic residues that are generated as by-products of commercial, industrial or agricultural activities, and are generally a large source of contamination, and so alternative uses for such waste are currently being investigated.

In this paper, we will present the use of coconut (Cocos nucifera) mesocarp fiber, considered a waste, to obtain cellulose nanofibrils to replace synthetic fibers. The textile sector is one of the major contributors to the deterioration of the environment. The main environmental impacts of this industry relate to the wastewater that it generates and the chemical load they contain. Other important problems are water and energy consumption, bad odors, solid waste, noise and the generation of atmospheric emissions.

In view of these negative aspects, alternative production forms have been developed in recent years to reduce contamination. Among them, biotechnological techniques have recently been introduced to recycle waste and create new generation materials such as nanoscopic subtances. As regards this point, nanocellulose is especially noteworthy since it is a biodegradable and environmentally friendly vegetable material with outstanding mechanical and structural properties, that represents a viable alternative to oil-derived materials. Being a product of natural origin, nanocellulose can be considered environmentally friendly, i.e., at the end of its useful life it can be discarded without causing harm to the environment; This type of compound can be called "biocomposite" or "green compound".

\section{Methodology}

The methodology was divided into two phases: fieldwork and experimentation.

${ }^{\star}$ Correspondence to: Neftalí Rojas-Valencia, National Autonomous University of Mexico, Institute of Engineering, Coordination of Environmental Engineering Building 5, cubicle 212, Avenida Universidad \# 3000, Colonia Coyoacán, Distrito Federal, México, Tel: +55 52-56-23-36-00 ext. 8663; E-mail: nrov@ pumas.iingen.unam.mx

Key words: coconut, fibers, nanofibrils, textiles

Received: February 19, 2018; Accepted: March 12, 2018; Published: March 15 2018 
During the first phase of the methodology, samples were taken from Mexico City's Central Market to obtain organic coconut fiber waste. We worked with the waste generated from coconut fiber from the state of Guerrero, which is the state of the Mexican Republic with the highest production of this crop.

The methodology implemented for the sampling by quartering method and the generation study in Mexico City's Central Market adhered to the guidelines stated in Mexican Standard NMXAA-15-1985. Environmental protection - Soil pollution - Municipal solid waste - Sampling - Quartering method. The second phase in the laboratory was divided into 5 stages. The first stage was the proximate and cell wall analysis of coconut residues to determine the humidity, amount of fiber, cellular content, hemicellulose and cellulose present in the waste.

Cellulose nanofibrils were obtained from coconut fiber residues during the second stage of experimentation. The chemical method used consists of three steps that are pre-wash, whitening and acid hydrolysis. In the pre-wash step, the coconut mesocarp was dried, crushed and cut as thin as possible and then washed with distilled water for 10 minutes, and then with water at $50^{\circ} \mathrm{C}$ for 2 hours, it was then filtered and the process was repeated twice. The residue was dispersed in $500 \mathrm{~mL}$ of $2 \%$ $\mathrm{NaOH}$ solution for 2 hours at $80^{\circ} \mathrm{C}$, filtered and washed with distilled water. The $\mathrm{NaOH}$ treatment was repeated once more for further removal of impurities. Finally, the resulting fibers were dried at $50^{\circ} \mathrm{C}$ for 24 hours. In the whitening step, the mass obtained was bleached in a solution of $1.5 \mathrm{~g}$ of sodium chlorite $\left(\mathrm{NaClO}_{2}\right)$ and $8-10$ drops of glacial acetic acid at a temperature ranging from 60 to $70^{\circ} \mathrm{C}$. Said mixture was stirred at constant intervals of one hour and then cooled in a tub filled with ice, filtered and washed again with water.

At the end, the paste obtained was treated with a $0.05 \mathrm{~N}$ nitric acid solution for one hour at $70^{\circ} \mathrm{C}$, screened through a $120 \mu \mathrm{m}$ mesh and subsequently washed with water. Next, an alkaline treatment was carried out with a $0.1 \mathrm{M} \mathrm{NaOH}$ solution at $45^{\circ} \mathrm{C}$ for 3 hours. Following this, successive treatments were carried out with $\mathrm{H}_{2} \mathrm{O}_{2}$, in the following volume percentages: $0.5 \%, 1 \%, 2 \%, 3 \%$ at $45^{\circ} \mathrm{C}$ for 15 hours in total at $\mathrm{pH}$ 11.5. Afterwards, an alkaline treatment was carried out with $10 \%$ $\mathrm{m} / \mathrm{v} \mathrm{NaOH}$ solution and $1 \% \mathrm{~m} / \mathrm{v} \mathrm{Na}_{2} \mathrm{~B}_{4} \mathrm{O}_{7}$ at $28^{\circ} \mathrm{C}$ for 15 hours.

Finally, an acid treatment was carried out with a solution of $80 \% \mathrm{v} / \mathrm{v}$ $\mathrm{CH}_{3}(\mathrm{COOH})$ and $70 \% \mathrm{v} / \mathrm{v} \mathrm{HNO}_{3}$ in a $10: 1$ ratio at $120^{\circ} \mathrm{C}$ for 15 minutes. Following the pre-wash and whitening of the fibers, an acid hydrolysis was performed with a $64 \%$ concentrated sulfuric acid solution for 30 minutes at $45^{\circ} \mathrm{C}$ under continuous stirring. The resulting pulp was washed and centrifuged for 10 minutes at 10,000 rpm. A precipitate was obtained. The resulting precipitate was continuously dialyzed with water for 3 days until a constant $\mathrm{pH}$ was reached. In the third stage of experimentation, the nanofibrils obtained were analyzed through a scanning electron microscope to determine their morphology and dimensions.

In the fourth stage, an electrospinning device was used to make yarn with the obtained nanofibrils. The solution used was based on the ionic liquid acetate of 1-ethyl-3-methylimidazolium and $\mathrm{N}$, $\mathrm{N}$-dimethylformamide to dissolve the nanofibrils at $45^{\circ} \mathrm{C}$ for 24 hours. After this dissolution, a solution of PCL/acetone was added and it was left under continuous agitation for 3 hours. The resulting solution was placed in a syringe, varying the volume, flow, voltage and distance from the collector. The fifth and last stage of the experimentation was the evaluation of technical, economic and environmental feasibility. Tensile strength tests were carried out on the obtained yarn and the results were compared with those obtained with synthetic fibers.

\section{Results}

Desk work showed that there is no proper management of organic solid waste from the agricultural industry in Mexico. A large amount of waste is generated, which is usually burnt by producers, creating thus another environmental problem.

Figure 1 shows the comparison of coconut crop production versus related waste generation. According to SAGARPA, 178,832.88 tons of coconuts were harvested in 2014, of which 62,591.51 tons correspond to the mesocarp and $116,241.37$ tons to the endocarp.

According to the proximate and cell wall analysis, coconut fiber waste contains $28.72 \%$ cellulose. In these residues the percentage of lignin and hemicellulose to be removed is $40.25 \%$ and $10.56 \%$, respectively. At the end of the whole process, $25 \mathrm{~g}$ of nanofibrils were obtained, which were used to perform the morphological analysis using a scanning electron microscope. Figure 2 shows the image obtained, where a porous fiber formed by fibers having a thickness ranging from 50 to 60 nanometers is observed; the composite fiber having a thickness of approximately $875 \mathrm{~nm}$.

In the elaboration of the yarn, we worked with an electrospinning device, varying the concentration of the material in the acetate solution of 1-ethyl-3-methylimidazolium and N, N-dimethylformamide. We worked with a percentage by weight of the material ranging from $12 \%$ to $16 \%$, this latter value showing better dissolution results. In the electrospinning device, a yarn was obtained from a flow of 3.5 to $8 \mathrm{~mL} / \mathrm{s}$, a voltage between 15 and $20 \mathrm{Kv}$ and collector distance of 15 to $20 \mathrm{~cm}$. Figure 3 shows the electrospinning device that was used and the yarn obtained.

The fibers (or yarn) obtained were analyzed by scanning electron microscope to determine their morphology. Figure 4 shows the image of the fibers obtained from the $16 \%$ coconut fiber solution and $99 \%$ PCL/acetone. A tangle of nanofibrils of a thickness ranging from 1.08 and $5.80 \mu \mathrm{m}$ is observed.

\section{Conclusion}

In Mexico City's Central Market, 250 to $300 \mathrm{~kg}$ of coconut fiber waste are generated per day. It is the first time that this generation data is obtained in Mexico, since there is no previous record of this information. Coconut fiber has properties that make it attractive for this work because it is resistant to biodegradation, durable and shows high tensile strength compared to other natural fibers. Moreover, this material has never been used as in this study. The yarn was obtained through the electrospinning technique, using a mixture of two

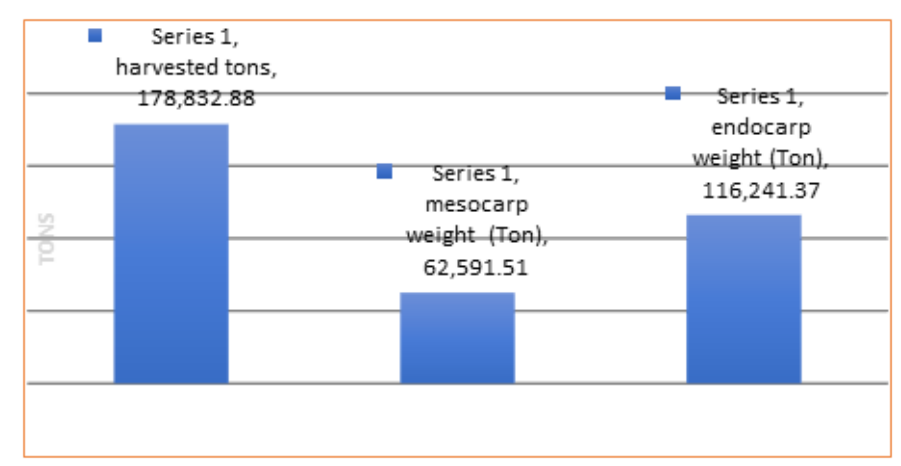

Figure 1. Harvested tons of coconut vs. fruit weight and waste. Mexico City's Central Market generates $300 \mathrm{~kg} /$ day of coconut waste. 


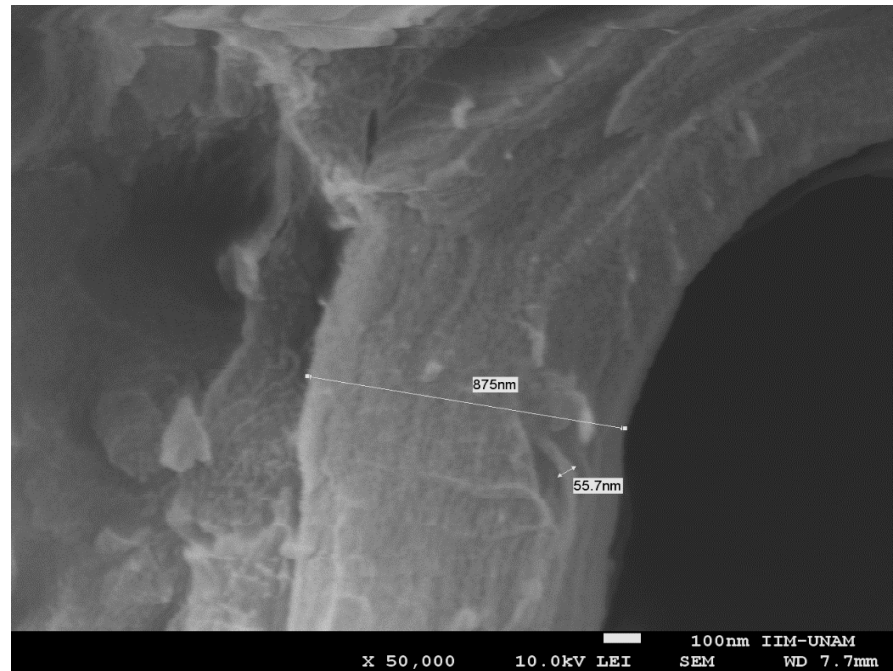

Figure 2. NFC Coconut.

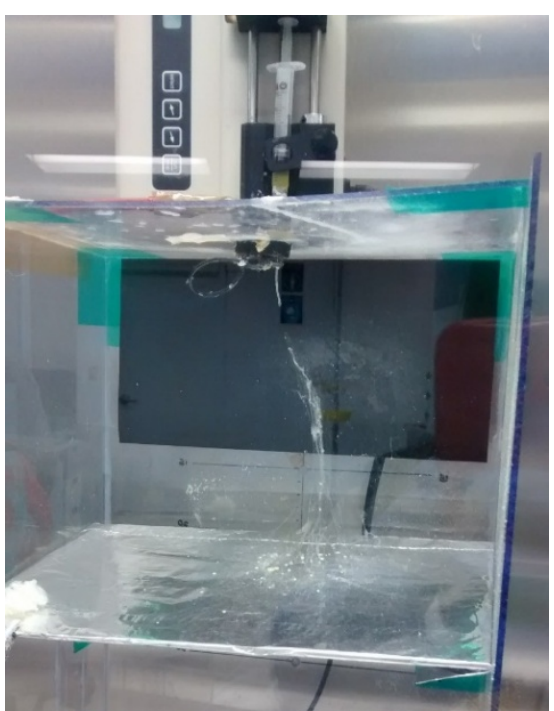

Figure 3. Yarn obtained by electrospinning.

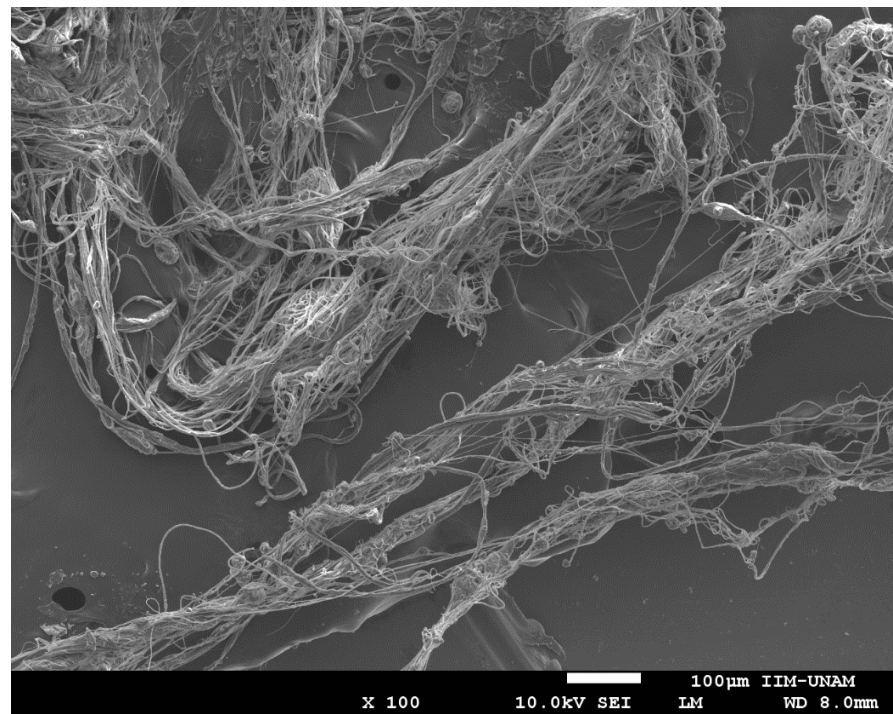

Figure 4. Electrospun fibers of $16 \%$ coconut fiber solution and $99 \% \mathrm{PCL} /$ acetone. solutions. It was determined that the $16 \%$ by weight solution was the most appropriate.

We thank the working team of the Unidad de Servicios de Información of the Institute of Engineering, UNAM, for locating useful references.

\section{References}

1. Abitbol T, Rivkin A, Cao Y, Nevo Y, Abraham E, et al. (2016) Nanocellulose, a tiny fiber with huge applications. Curr Opin Biotechnol 39: 76-88.

2. Ahn Y, Hyun-Lee S, Joo-Kim H, Yang Y, Hong J, et al. (2012) Electrospinning of lignocellulosic biomass using ionic liquids. Carbohydr Polym 88: 395-398.

3. Beck-Candanedo S (2005) Effect of reaction conditions on the properties and behavior of suspensions of cellulose nanocrystals in wood. Department of Chemistry, Pulp and Paper Research Centre, McGill University, Montréal, Québec.

4. Cazaurang M, Peraza S, Cruz R (1990) Dissolution of henequen fiber grade pulps. Cellulose Chemistry and Technology pp: 629-638.

5. Duque L, Rodriguez L, López M (2013) Electrospinning: the era of nanofibers. Iberoamerican Polymer Magazine 14: 10-27.

6. FECYT (2009) Nanoscience and nanotechnology. Between the science fiction of the present and the technology of the future. Spanish Foundation for Science and Technology pp: 20-44.

7. Ferrer A (2013) Comprehensive use of the residue of the palm oil industry. Obtaining derivatives of hemicelluloses, cellulose pulps and nanofibrillar cellulose. University of Cordoba.

8. Figueiredo M, Freitas Rosa M, Lie Uhaya C, Souza Filho M, Cameiro A, et al. (2012) Life cycle evaluation of cellulose nanowhiskers. J Clean Prod 35: 130-139.

9. Hernandez C, Rosa S (2016) Extraction of cellulose nanowhiskers: source of natura fibers, methodology and application. Polymer Science: research advances, practical applications and educational aspects 1: 232-242.

10. Ibrahim M, El-Zawawy W, Nassar M (2010) Synthesis and characterization of film of polyvinyl alcohol / nanospheric cellulose particles. Carbohydr Polym 79: 694-699.

11. López A (2004) Influence of the recycling process on the properties of the composite materials obtained by injection of polystyrene reinforced with lignocellulosic fibers. Doctoral thesis. University of Girona, Spain.

12. Mittal A, Chisti Y, Chand U (2013) Synthesis of metallic nanoparticles using plant extracts. Biotechnol Adv 31: 346-356. [Crossref]

13. Ohkawa K (2015) Nanofibers of cellulose and its derivatives fabricated using direct electrospinning. Molecules 20: 9139-9154. [Crossref]

14. Pillai K (2011) Bio-inspired cellulose nanocomposites. Doctoral thesis. Blacksburg, Virginia. Virginia Polytechnic Institute and State University.

15. Ramsden J (2009) Applied Nanotechnology The conversion of research results to products. William Andrew, pp: 27-36.

16. Robles M, Rodríguez-Félix F, Márquez-Ríos E, Barrera A, Aguilar J, et al. (2014) Biomedical, textile and food applications of nanostructures produced by electrospinning. J Biol Sci Health 16: 44-52.

17. Rosa M, Medeiros E, Malmonge J, Gregorski K, Wood D, et al. (2010) Nanowhiskers of cellulose of coconut shell fibers: effect of the conditions of preparation on its thermal and morphological behavior. Carbohydr Polym 81: 83-92.

18. Satyanarayana E (2009) Biodegradable materials based on lignocellulosic fiber - A general vision. Prog Polym Sci 34: 989-1021.

19. Ureña E (2011) Properties and applications of cellulose nanocrystals in renewable nanocomposites. Doctoral thesis. Clemson, South Carolina. Clemson University.

20. Williams L, Adams W (2007) Nanotecnología desmitificada. New York: McGraw Hill: 255

Copyright: (C2018 Rojas-Valencia MA. This is an open-access article distributed under the terms of the Creative Commons Attribution License, which permits unrestricted use, distribution, and reproduction in any medium, provided the original author and source are credited. 